\title{
Bacteriology and Antibiotic Sensibility Associated with Extracted Carious Teeth: A Cross Sectional Study at Komfo Anokye Teaching Hospital, Kumasi, Ghana
}

\author{
Ama Agyeibea Amuasi ${ }^{1}$, Alexander Oti Acheampong ${ }^{*}$, Collins Kokuro ${ }^{1}$, Alex Ofori ${ }^{1}$, \\ Kpedekpo Yayra ${ }^{2}$, Joseph Abu-Sakyi', Francis Adu-Ababio ${ }^{1}$ \\ ${ }^{1}$ School of Medicine and Dentistry, Kwame Nkrumah University of Science and Technology, Kumasi, Ghana \\ ${ }^{2}$ Komfo Anokye Teaching Hospital, Kumasi, Ghana \\ Email: *aotiacheampong@yahoo.com
}

How to cite this paper: Amuasi, A.A., Acheampong, A.O., Kokuro, C., Ofori, A., Yayra, K., Abu-Sakyi, J. and Adu-Ababio, F. (2020) Bacteriology and Antibiotic Sensibility Associated with Extracted Carious Teeth: A Cross Sectional Study at Komfo Anokye Teaching Hospital, Kumasi, Ghana. Open Journal of Stomatology, 10, 87-96.

https://doi.org/10.4236/ojst.2020.105010

Received: February 26, 2020

Accepted: May 9, 2020

Published: May 12, 2020

Copyright $\odot 2020$ by author(s) and Scientific Research Publishing Inc. This work is licensed under the Creative Commons Attribution International License (CC BY 4.0).

http://creativecommons.org/licenses/by/4.0/ (c) (i) Open Access

\begin{abstract}
Background: Many oral bacterial species forming the normal flora present as a biofilm in the oral cavity. Dental caries results when there is an imbalance of pathogenic bacteria within these biofilms. Aim: This study sought to isolate and identify the bacterial species associated with extracted carious teeth and their susceptibility pattern towards commonly employed antimicrobial agents used at the Komfo Anokye Teaching Hospital (KATH). Methodology: A descriptive cross-sectional study carried out on thirty-three extracted carious teeth samples collected by convenient sampling from patients attending the Oral Health Directorate-KATH. All samples were collected from the $11^{\text {th }}$ of March 2019 to the $6^{\text {th }}$ of April 2019. Data was collected using $5 \mathrm{ml}$ peptone water and a case study form. Analysis was done using SPSS version 25 and Microsoft Excel version 10. Results: Twenty (61\%) samples were obtained from female patients and thirteen samples (39\%) from male patients. Streptococcus spp had the highest occurrence (32.25\%) with the least isolated being Pseudomonas and E. coli spp (6.45\%). Antibiotic susceptibility test revealed Pseudomonas spp was resistant to all the eight antibiotics used in this study. All bacterial isolates were resistant to Cefuroxime and penicillin except Staphylococcus and Streptococcus spp. Conclusion: The commonest isolates associated with dental caries in KATH were Streptococcus, Bacillus and Staphylococcus spp. In this study most of the isolated species were resistant to common antibiotics employed in the Oral Health Directorate in KATH (amoxicillin/clavulanic, ampicillin and penicillin). From the current study the most effective antibiotic observed was meropenem (23\%) with penicillin (3\%) being least effective in treating infections of caries.
\end{abstract}




\section{Keywords}

Caries, Bacteria, Teeth, Antibiotic, Resistance

\section{Introduction}

The oral cavity extends from the lips to the opening of the trachea immediately behind the wisdom teeth and contains the tongue with numerous glands, the oral mucosa, the teeth and nearly 1000 identified bacterial species forming a dynamic ecosystem which may be inconsistent in its natural habitat [1] [2]. The oral environment is usually moist, enriched with compounds such as carbohydrates, lipids and proteins that provide conducive conditions for normal flora and occasionally serving as a medium of growth for some pathogenic bacteria [3].

Dental caries or decay is commonly known in Ghana as "kaka" in Twi and Ga, and "aduvovo" in Ewe. It is a dynamic process characterized by an episodic demineralization and remineralization of the hard tissues of teeth mainly enamel and dentin by bacterial activity over time. Dental caries is a significant, sugar dependent infectious disease worldwide affecting humans throughout their lifetime, from childhood through to senile years causing toothache tooth loss in the oral cavity and loss of productivity [4] [5] [6].

A main determining factor of dental caries is a lifestyle and starts at a point where oral hygiene and nourishment are neglected even for a period as short as a few weeks [7] [8]. The clinical presentation of dental caries differs from the stage of development although the risk factors are similar. The carious process can be stopped or reversed at an early stage. However, if left untreated the disease may cause dysfunctions of the masticatory system, systemic infections of odontogenic origin and sometimes death.

Over the years, epidemiological studies have indicated a differential incidence of caries in various countries due to advancements such as water fluoridation, use of fluoride toothpaste, a healthier diet and oral health education leading to many developed countries having observed a reduction in the prevalence of the disease [9] [10].

In developing countries such as Ghana, the prevalence of dental caries still remains high. Quist [11] found the prevalence of dental caries among patients attending the dental unit of the Tema General Hospital, in Ghana to be $81.3 \%$ with $92.3 \%$ having complete destruction of the tooth. Variation in prevalence pattern of dental caries is related to sex, age, socio-economic status, geographical location, race, dietary habits and oral hygiene practices [12]. Dental caries can be seen in the oral cavity by visual inspection, and aided by diagnostic methods such as radiographic imaging, Quantitative Light-induced Fluorescence, DIAGNOdent and electrical conductance in the detection of the less visible carious decay [13]. 
Antibiotics are often prescribed as an adjunct in the treatment of dental caries with pulpal involvement or abscesses to localize or minimize the spread of infection. Antibiotic susceptibility testing measures antibiotic resistance pattern of bacteria and the preference of an antibiotic is usually based on published susceptibility testing and previous clinical success [14]. Susceptibility testing prior to antibiotic administration could improve treatment outcomes in cases of infection. [15].

The aim of this study was thus to isolate and identify bacterial species associated with dental caries and their susceptibility to commonly used antibiotics at the Komfo Anokye Teaching Hospital (KATH).

\section{Methods and Statistics}

This was a descriptive cross-sectional study to determine the bacteria associated with dental caries in KATH. The study sample was selected from the dental care seeking population using convenient sampling method, a non-probability sampling technique amongst patients attending the dental clinic in the Oral Health Directorate of KATH.

\subsection{Sample Size Calculation}

General Dental care seekers at KATH in 2018 ( 1 yr $)=28,000$

Dental care seekers at KATH over 4 months $=\frac{4}{12} \times 28000=9333$

Extractions due to dental caries over 4 months duration (from KATH records) $=179$

$$
\begin{aligned}
& \text { Prevalence of extractions resulting from dental caries } \\
& \begin{aligned}
=\frac{179}{9333} \times 100 & =1.92 \% \approx 2 \%=0.02 \\
\text { Sample size } & =\frac{Z^{2}(P)(1-P)}{d^{2}}=\frac{1.96^{2}(0.02)(1-0.02)}{0.05^{2}} \\
& =30+10 \% \text { attrition rate } \\
& =30+3 \\
& =33
\end{aligned}
\end{aligned}
$$

where $Z$ is the standard normal variate $=1.96$

Confidence interval $=95 \%$

$P$-Expected proportion in population due to previous studies

$d$-Absolute error/precision

For patients who consented to the study, a single extracted tooth was obtained. The tooth sample was used for the study. $15 \mathrm{~g}$ of peptone powder was dissolved in 1 liter of distilled water. The solution was well mixed and an aliquot of $5 \mathrm{ml}$ of peptone water was dispensed into falcon tubes and autoclaved at $121^{\circ} \mathrm{C}$ for 15 minutes to maintain sterility (Picture 1 ).

All samples were collected from the $11^{\text {th }}$ of March 2019 to the $6^{\text {th }}$ of April 2019. Sterile cotton swabs were used to acquire carious debris from extracted carious teeth by using a swab or scoop technique. This involved embedding the 
swab stick into the area of carious lesion for two minutes, twisting the swab stick gently, then placing into $5 \mathrm{ml}$ aliquot of sterile peptone water in falcon tubes (Picture 2). These were subsequently transported to the bacteriology laboratory of the Department of Microbiology in KATH. Nutrient agar was prepared by dissolving $11.2 \mathrm{~g}$ of agar in $400 \mathrm{ml}$ of distilled water in a $500 \mathrm{ml}$ conical flask. The solution obtained was heated on a hot stove till the entire agar was completely dissolved, poured into test tubes, covered with cotton and autoclaved for 45 minutes at $121^{\circ} \mathrm{C}$. The sterile medium was then placed in a water bath to cool for 15 minutes. The preparation of media was done at the Microbiology Department of KATH.

\subsection{Isolation of Bacterial Species}

A ration of suspension from each sample was streaked on sheep blood agar and MacConkey agar and incubated at $37^{\circ} \mathrm{C}$ for $24 \mathrm{hrs}$ (Picture 3). Gram staining was performed [16] to identify bacterial species based on their size, shape, color, surface characteristics of the colony. Discrete bacterial colonies from pure culture plates were subjected to oxidase, catalase and coagulase test to further identify specific bacterial species according to the United Kingdom standards for microbiology. Antibiotic susceptibility testing was done using the Kirby Bauer disc diffusion method on Muller Hinton Agar [17]. The antibiotics used in the susceptibility testing were Cefuroxime (30 $\mu \mathrm{g})$, Erythromycin (15 $\mu \mathrm{g})$, Ampicillin

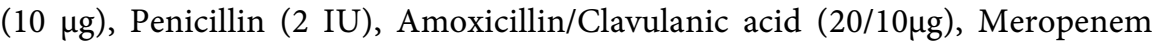
$(10 \mu \mathrm{g})$, Cotrimoxazole $(1.25 \mu \mathrm{g})$, and Ciprofloxacin $(5 \mu \mathrm{g})$.

Each isolated bacterial strain was inoculated into Mueller-Hinton Agar with antibiotic disc and incubated at $37^{\circ} \mathrm{C}$ for 24 hours. The zones of inhibition of each antibiotic disc against the different bacterial species were recorded and interpreted according to the clinical laboratory standards institution guidelines (Picture 4).

Data analysis was undertaken using Statistical Package for Social Sciences (SPSS) version 25 and Microsoft Excel version 10 to deduce and interpret results.

Ethical approval for the study was obtained from the Committee on Human Research, Publications and Ethics of the Kwame Nkrumah University of Science and Technology, Research and Development Unit KATH, the Oral health directorate KATH and the Bacteriology laboratory KATH.

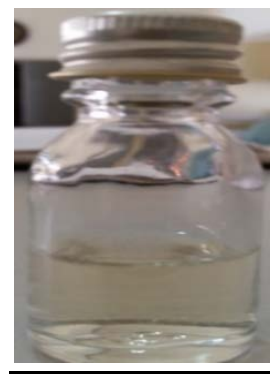

Picture 1. Sample bottle containing peptone water $\times 0.5$. 


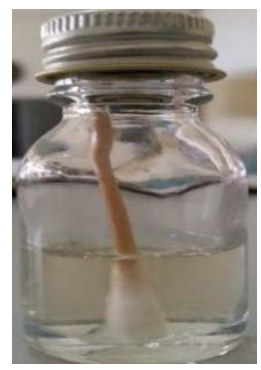

Picture 2. Sample bottle containing swab with carious debris $\times 0.5$.

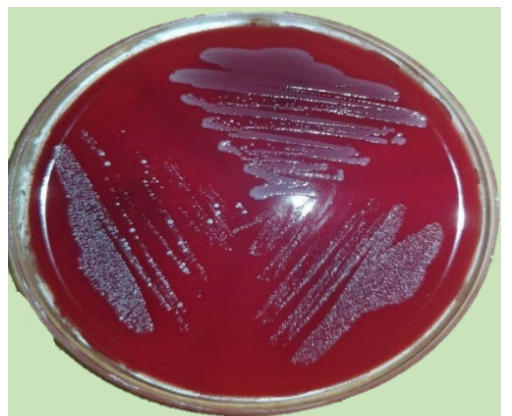

Picture 3. Picture showing bacterial growth on sheep blood agar $\times 0.5$.

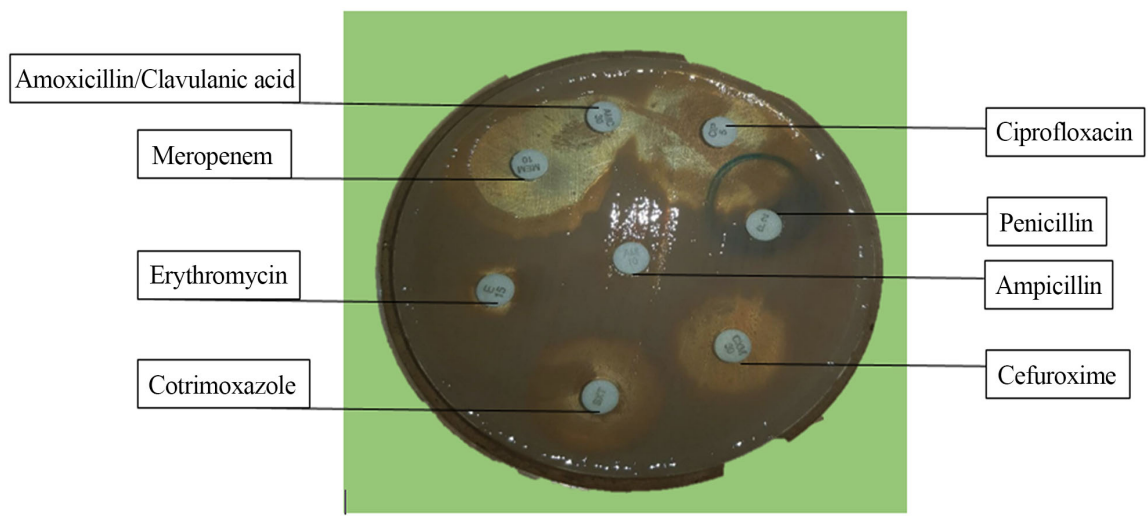

Picture 4. Picture of bacterial isolate showing zone of inhibition and no zones of inhibition against selected antibiotics on Muller-Hinton agar $\times 0.5$.

\section{Results}

A total of 33 extracted teeth samples were used for the study. 7 swab samples and 26 scoops of carious lesions samples were collected representing a $100 \%$ sample size. In terms of bacteria isolate characterization, 10 isolates of Streptococcus spp. were obtained from the 33 cultured samples representing $31 \%$ of all attained isolates. The least isolates were E. coli and Pseudomonas spp each with 2 isolates each representing $6 \%$ of the total isolates.

\subsection{Colony Count}

The highest microbial isolates were recorded for the serial dilution factor of $10^{6}$ 
with 12 samples representing $37 \%, 10^{8}$ with $30 \%, 10^{7}$ with $21 \%$ and the least was $10^{5}$ with $12 \%$ (Figure 1 and Figure 2).

\subsection{Susceptibility}

The susceptibility pattern for the antibiotics used was highest for Meropenem at $23 \%$, this was followed by Cefuroxime at $17 \%$, Cotrimoxazole recorded susceptibility at 16\%, the susceptibility for Ampicillin was 12\%, Amoxicillin/Clavulanic Acid had 11\% susceptibility, 10\% for Erythromycin, $8 \%$ for Ciprofloxacin and the lowest susceptibility percentage was $3 \%$ for Penicillin (Figure 3 ).

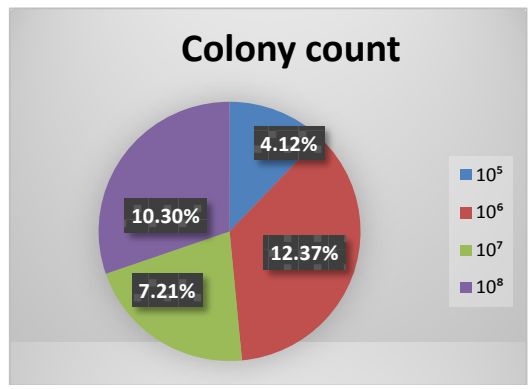

Figure 1. Diagram showing microbial colony count.

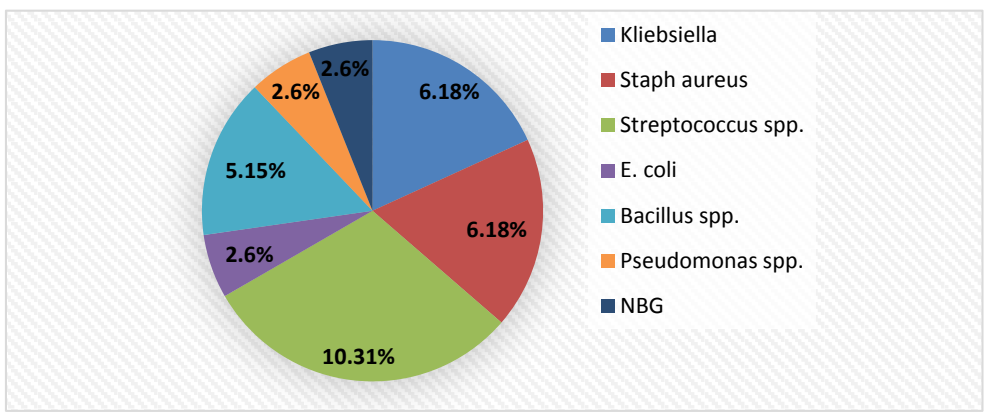

Figure 2. Diagram showing cultivated bacterial isolates.

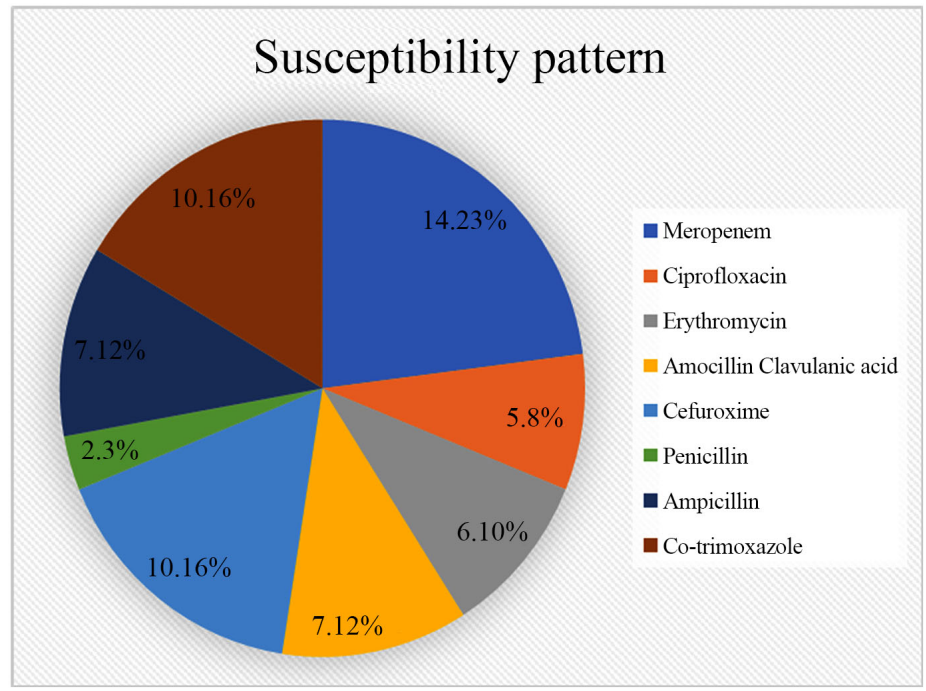

Figure 3. Antibiotic susceptibility pattern. 


\subsection{Resistance}

The resistance percentages for the isolated bacteria was found to be $17 \%$ of Penicillin, 14\% of both Erythromycin and Amoxicillin/Clavulanic acid, 13\% of Cefuroxime, $12 \%$ of Ampicillin and Cotrimoxazole and the least resistance was $9 \%$ of Meropenem and Ciprofloxacin (Figure 4).

\section{Discussion}

The distribution of isolates observed is comparative with a study conducted at the Dental Unit of the General Hospital of Minna in Nigeria in which authors used tooth samples from 40 patients [17]. In this study, Staphylococcus aureus had the highest occurrence with 31 isolates, followed by Streptococcus mutans with 23 isolates, and Lactobacillus spp with 4 isolates [18].

This study disclosed Streptococcus spp had the highest occurrence with 10 isolates, followed by Klebsiella spp and Staphylococcus spp with 6 isolates, Bacillus spp recorded 5 isolates and the least isolates recorded was Pseudomonas spp and $E$. coli spp with 2 isolates each.

Few species of Pseudomonas spp and $E$. coli spp were identified in some samples, but the predominant isolates were Streptococcus spp and Klebsiella spp. This submits that Klebsiella spp and Streptococcus spp were the most prevalent isolated bacterial species and significantly responsible for the development of dental caries observed in the study.

The isolated bacterial species corroborate earlier reported cases in Nigeria and other parts of the world that documented Lactobacillus spp and Streptococcus mutans as the commonest bacteria associated with dental caries. In a similar study conducted at the Rajah Muthiah Dental College and Hospital Annamalai University, they isolated Streptococcus mutans, Klebsiella pneumoniae, Staphylococcus albus, Proteus vulgaris and Pseudomonas aeruginosa as bacteria implicated in dental caries [19].

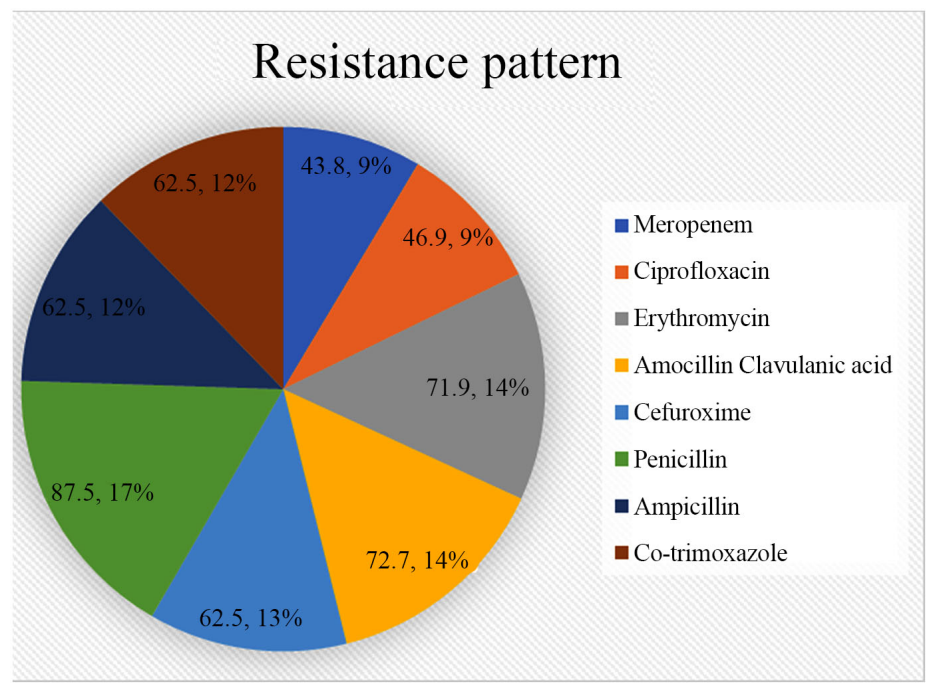

Figure 4. Antibiotic resistance pattern. 
Equal number of isolates was realized for Gram positive bacteria (50\%) and Gram-negative bacteria (50\%) in dental caries (Table 1). Other authors recorded $100 \%$ of bacterial isolates associated with dental caries being Gram-positive [20]. Yadav \& Prakash reported 90\% of isolates as being Gram-positive bacteria and $10 \%$ being Gram-negative bacteria. In addition, study results of identifying facultative anaerobes $(66.67 \%)$ and aerobes $(33.33 \%)$ are consistent with findings by where author isolated 87 bacterial species, out of which $72.41 \%$ were facultative anaerobes and $27.59 \%$ were anaerobes giving credence to this study [11].

With regards to the susceptibility pattern of antibiotics against bacterial isolates, it was highest for Meropenem (23\%), followed by Cefuroxime (17\%), Cotrimoxazole (16\%), Ampicillin (12\%), Amoxicillin/Clavulanic Acid (11\%), Erythromycin (10\%), Ciprofloxacin (8\%) and Penicillin (3\%), (Figure 3). Results from the study on resistance of bacterial isolates to antibiotics were highest for Penicillin (17\%), with Erythromycin and Amoxicillin/Clavulanic acid following (14\%), Cefuroxime being third (13\%), Ampicillin and Cotrimoxazole fourth (12\%) and lastly Meropenem and Ciprofloxacin being the least resistant (9\%), (Figure 2). The resistance and susceptibility pattern in this study was similar to that of Dwivedi et al. [21], who found similar resistance percentages of bacterial isolates to penicillin $\mathrm{V}$, erythromycin, penicillin $\mathrm{V} /$ amoxicillin and amoxicillin/erythromycin.

\section{Limitations of Study}

This study did not take into account the degree of dental caries progression in each participant and the duration the participant had had the disease for thus limiting the full knowledge of bacterial isolates present as the disease dental caries progresses. Another limitation may be the operative errors in taking swab and scoop samples of caries debris from extracted teeth.

\section{Conclusions}

Majority of the bacterial isolates observed were Streptococcus spp whilst the least isolates were observed for Bacillus, Pseudomonas and E. coli spp. The number of bacterial isolates identified in this study was highest in the Oral and Maxillofacial Department of the Oral Health Directorate with Child Oral Health and Orthodontics Department recording the least isolates. Three of the isolates (Streptococcus, Bacillus and Staphylococcus spp) were found to be common in all departments the other two of which are Department of Adult Oral Health and

Table 1. Table showing identification of different cultivated bacterial isolates.

\begin{tabular}{cc}
\hline Gram positive isolates & Gram negative isolates \\
\hline Streptococcus spp (Facultative anaerobe) & Klebsiella spp (Facultative anaerobe) \\
Staphylococcus spp (Facultative anaerobe) & E. coli spp (Facultative anaerobe) \\
\hline
\end{tabular}


Department of Oral Diagnosis making a total of four departments in the Oral Health Directorate of KATH. Four other bacterial isolates were also associated with dental caries but not common across all departments.

The study revealed that most of the isolated species were resistant to the common antibiotics employed in the Oral Health Directorate in KATH (amoxicillin/clavulanic, ampicillin and penicillin). The study reveals meropenem (23\%) as being most effective antibiotic observed, followed by cefuroxime (16\%) and cotrimoxazole (16\%). The resistance pattern observed was highest for penicillin.

\section{Recommendation}

A recommendation for a culture and sensitivity test prior to antibiotic treatment initiation in dental caries could help curb the antibiotic resistance often observed among patients. A larger sample size study is recommended in validating these findings. A future study on the determination of subspecies isolates can support the explanation of the pattern of resistance observed.

\section{Conflicts of Interest}

The authors declare no conflicts of interest regarding the publication of this paper.

\section{References}

[1] Lazarevic, V., Whiteson, K., Hernandez, D., François, P. and Schrenzel, J. (2010) Study of Inter- and Intra-Individual Variations in the Salivary Microbiota. BMC Genomics, 11, 523. https://doi.org/10.1186/1471-2164-11-523

[2] Marsh, P.D. (2005) Dental Plaque Biological Significance of a Biofilm and Community Life Style. Journal of Clinical Periodontology, 32, 7-15. https://doi.org/10.1111/j.1600-051X.2005.00790.x

[3] Borty, S.C., Hafiz, K.M.B., Ali, M.M., Begum, K., Ahammed, T., Monir, M.S. and Islam, M.A. (2015) Isolation, Identification and Antibiogram Profile of Bacteria Isolated from Dental Caries Patients of Mymensingh District of Bangladesh. Asian Journal of Medical and Biological Research, 1, 244-253. https://doi.org/10.3329/ajmbr.v1i2.25618

[4] Featherstone, J.D. (2004) The Caries Balance: The Basis for Caries Management by Risk Assessment. Oral Health \& Preventive Dentistry, 2, 259-264.

[5] Edelstein B. (2006) The Dental Caries Pandemic and Disparities Problem. BMC Oral Health, 15, S2. https://doi.org/10.1186/1472-6831-6-S1-S2

[6] Yoo, S.Y., Park, S.J., Jeong, D.K., Kim, K.W., Lim, S.H., Lee, S.H. and Kook, J.K. (2007) Isolation and Characterization of the Mutans Streptococci from the Dental Plaques in Koreans. The Journal of Microbiology, 45, 246-255.

[7] Nyvad, B. and Fejerskov, O. (1997) Assessing the Stage of Caries Lesion Activity on the Basis of Clinical and Microbiological Examination. Community Dentistry and Oral Epidemiology, 25, 69-75. https://doi.org/10.1111/j.1600-0528.1997.tb00901.x

[8] Ten Cate, J.M. (2001) What Dental Diseases Are We Facing in the New Millennium: Some Aspects of Research Agenda. Caries Research, 35, 2-5.

https://doi.org/10.1159/000049100 
[9] Konig, K.G. (2004) Clinical Manifestations and Treatment of Caries from 1953 to Global Changes in the 20th Century. Caries Research, 38, 168-172. https://doi.org/10.1159/000077751

[10] Marthaler, T.M. (2004) Changes in Dental Caries 1953-2003. Caries Research, 38, 173-181. https://doi.org/10.1159/000077752

[11] Quist, S. (2016) Prevalence of Dental Caries in Patients Attending the Dental Clinic of the Tema General Hospital. University of Ghana, Ghana. http://ugspace.ug.edu.gh

[12] Yadav, K. and Prakash, S. (2015) Antibiogram Profiles against Polymicrobial Pathogens among Dental Caries Patients at Janaki Medical College Teaching Hospital, Nepal. International Journal of Applied Dental Sciences, 1, 156-162.

[13] Fejerskov, O. (2004) Changing Paradigms in Concepts on Dental Caries: Consequences for Oral Hath Care. Caries Research, 38, 182. https://doi.org/10.1159/000077753

[14] Devi, B.P. and Ramasubramaniaraja, R. (2009) Dental Caries and Medicinal Plants: An Overview. Journal of Pharmacy Research, 2, 1669-1675.

[15] Rahman, M., Islam, M.N., Islam, M.N. and Hossain, M.S. (2015) Isolation and Identification of Oral Bacteria and Characterization for Bacteriocin Production and Antimicrobial Sensitivity. Dhaka University Journal of Pharmaceutical Sciences, 14, 103-109. https://doi.org/10.3329/dujps.v14i1.23742

[16] Harley, J.P. and Prescott, L.M. (1996) Laboratory Exercises in Microbiology.

[17] Drew, W.L., Barry, A.L., O’Toole, R. and Sherris, J.C. (1972) Reliability of the Kirby-Bauer Disc Diffusion Method for Detecting Methicillin-Resistant Strains of Staphylococcus aureus. Applied and Environmental Microbiology, 24, 240-247. https://doi.org/10.1128/AEM.24.2.240-247.1972

[18] Daniyan, S.Y. and Abalaka, M.E. (2011) Prevalence and Susceptibility Pattern of Bacterial Isolates of Dental Caries in a Secondary Health Care Institution, Nigeria.

[19] Fayaz, M., Sivakumaar, P.K. and Joe, M.M. (2014) Prevalence and Antibiotic Susceptibility Pattern of Dental Biofilm Forming Bacteria. International Journal of Current Microbiology and Applied Sciences, 3, 46-50.

[20] Hassan-Olajokun, R.E., Folarin, A.A., Olaniran, O. and Umo, A.N. (2008) The Prevalent Bacterial Isolates of Dental Caries in School Age Children Attending the Dental Clinic of Oauthc, Ile-Ife. African Journal of Clinical and Experimental Microbiology, 9, 103-108. https://doi.org/10.4314/ajcem.v9i2.7490

[21] Dwivedi, H.P. and Jaykus, L.A. (2011) Detection of Pathogens in Foods: The Current State-of-the-Art and Future Directions. Critical Reviews in Microbiology, 37, 40-63. https://doi.org/10.3109/1040841X.2010.506430 